\title{
The medical librarian - the unsung enablers of military academic medicine
}

\begin{abstract}
Medical librarians in the United States are becoming a more frequently utilized resource for medical teams. With the recent advancements in information computerization, they are being even more heavily relied upon to help provide on-demand access to information. This article explores the evolving relationship between medical librarians in the academic military setting. The San Antonio Military Medical Center (SAMMC) medical library team collaborated with physician-researchers within the Department of Orthopaedic Surgery to not only accelerate research projects exceeding \$12M in Extra-Mural funding but also enable increased clinician time available for patient care. Highlighting the incredible efforts of the library staff at an academic military medical center can help clarify their roles and capabilities while alerting researchers to the potentially untapped resources in their own medical libraries.
\end{abstract}

Volume 9 Issue 4 - 2017

\author{
Anthony E Johnson,' Daniel Rodkey, ${ }^{2}$ Taylor \\ Bates $^{2}$ \\ 'Department of Orthopaedic Surgery, San Antonio Military \\ Medical Center, USA \\ ${ }^{2}$ Tufts University, USA
}

Correspondence: Anthony E Johnson, Chairman, Department of Orthopaedic Surgery, San Antonio Military Medical Center, USA Email Anthony.e.johnson.mil@mail.mil

Received: October 12, 2017 | Published: November 16, 2017

\section{Introduction}

The modern day interdisciplinary medical team is comprised of people from many professions. Medical librarians are an underutilized and often unrecognized component of medical teams, helping to provide optimal patient care through efficient data gathering and dissemination of knowledge. The librarians at San Antonio Military Medical Center (SAMMC) are one poignant example of the critical role of their profession. A PLOS survey conducted in 2015 showed librarians are recognized as contributors only $64 \%$ of the time. ${ }^{1}$ Medical librarians combine human skills with technology know-how to provide interdisciplinary collaboration. ${ }^{2}$

The library team at SAMMC is under the command of the Army Medical Department (AMEDD). Within AMEDD there are 37 librarian positions, 34 library technician positions, and 4 positions for technical information specialists. ${ }^{3}$ Two librarian positions are located at SAMMC. ${ }^{3}$ This article examines the education and training required to serve as a librarian, their role in military medicine, and what value they add to the healthcare team.

\section{A case example}

In August of 2016, research at SAMMC required approximately 200 interlibrary loan document requests. The library staff members who collaborated with the research team to help meet project deadlines include Grace McFarland, Janet Williams, and Patricia Thompson. This group worked adeptly and efficiently to obtain these documents for the research teams within one month This efficiency allowed for the initiation of over 15 individual research projects - 2 of which were completed and submitted for publication within the same time period.

\section{Discussion}

The profession dates as far back as $\sim 300$ BCE where libraries existed in ancient Egypt, Syria and Greece. Today, modern health sciences librarians continue to serve in traditional roles such as administration, book and journal selection, cataloging/classification, reference, and history. ${ }^{4}$ However, their skillset evolved to include new roles as computers and virtual digital data became ubiquitous. ${ }^{5}$ Bibliographies that would take hours to compile by hand could be produced in a matter of minutes with the development of digital information retrieval. ${ }^{4}$ As experts in information collection, today's librarians are often involved in informatics, data mining, teaching, and publication. ${ }^{4-6}$ This has led to the specialization of many librarians in different fields such as government, theology, law, and medicine.

The increasing importance of their role in healthcare has led us to examine more closely the credentials, role and value of librarians at an academic military medical center.

\section{Credentials}

Education for all librarians begins with a master's degree in Library Science. Library Sciences is defined as the study of collecting, preserving, cataloging, and making available books and other documents in libraries. ${ }^{7}$ In addition to a master's degree, librarians at SAMMC have additional training in medical terminology, anatomy and physiology. Some settings require a second master's degree, though this is not a requirement for Army librarians. ${ }^{3}$ Professional organizations exist, such as the Special Libraries Association and the Medical Library Association. In a recent study of academic and independent medical centers, more than half of librarians received faculty status. ${ }^{2}$

\section{Role}

Cooper et al identified twenty new roles of health sciences librarians from 1990 to 2012. The librarians at SAMMC work in many of these areas. Various specialties include archives, collection development, acquisition, electronic resources, outreach/public service, systems and research. Likewise, a systematic review of changing roles of health science librarians indicates other specialties such as translational research, clinical medicine, systematic reviews, clinical librarianship, and continuing medical education. ${ }^{5}$

Ms. Beatrice Nichols, MLS, of the Army Medial Department (AMEDD) Library Program Office believes that the most common scenario in which librarians are being underutilized is when they are excluded from settings and communication that would enable them to serve as an active member of the medical team. She states, when the librarian [attends] monthly meeting of the research committee, s/ he can evaluate collections proactively. For example, when I heard about an upcoming study on medical acupuncture, I was able to go back to my library and see what we had and line up resources to meet the needs my researchers would have before they asked...too often, 
though, the librarian is rather secluded from the life and pulse of the hospital. ${ }^{3}$

Freiburger et $a 1 .{ }^{8}$ described the success of embedding librarians within research teams at the Arizona Health Sciences Library (AHSL). ${ }^{8}$ One liaison librarian was spending close to $95 \%$ of her time in the college of public health after only one year of placing librarians among researchers to provide on site information services. Within that year she had served on faculty committees and grant teams, provided literature searches for 16 grant applications, and regularly taught information literacy components in 4 courses while working with faculty. ${ }^{8}$ Placing the librarian in a convenient location contributed to the success of liaison librarians. After petitioning the college, the librarian cubicle was relocated from a location next to the student lounge to a cubicle located on the faculty office floor. ${ }^{8}$ This allowed for convenient scheduled and unscheduled visits. Freiburger et al. explain that in this environment, "librarians are viewed as partners who can contribute significantly to the mission of the colleges and the university".

In a prospective controlled study, Aitken et al. found that assigning a clinical librarian to a patient care team had positive effects on provider attitudes, information retrieval tendencies, and clinical decision making. ${ }^{9}$ Their study showed librarians contributed through "the three key elements of intervention": librarian teaching, on-demand searching, and anticipatory provision of information to clinicians. ${ }^{9}$

Teaching is often identified as an important role of librarians. One study found medical librarians were active participants in the design, deployment, and assessment of students in Evidence-Based Medicine Curricula. ${ }^{5,6}$ Training for this role is acquired in both formal (i.e., medical education scholars program) and non-formal settings (i.e., self directed and on the job). ${ }^{6}$

\section{Value}

The value of an information expert in an academic military medical center is difficult to quantify. One finding from the 2011 Federal Libraries Value survey reported that physicians saved an average of four hours of time for each document that was procured for them. In the Case Example from SAMMC when the library worked to orchestrate 200 interlibrary loan documents, this translated to approximately 800 hours - or twenty 40 -hour work weeks. This represents a corresponding economic benefit of 800 hours that the physician-researchers can potentially spend with patients.

Measures of medical librarian value include time saved, value of resource collection, cost avoidance, and revenue generated from accepted grants. ${ }^{10}$ One study found that utilizing librarian-provided services that directly related to patient care decreased the length of stay. ${ }^{11}$

In an academic center, librarian-directed training sessions improve provider's ability to research clinical questions. One study found that residents that received librarian training decreased the time required to answer a question from 20 minutes to 13 minutes. If a resident physician answers as few as 3 clinical questions, that is over 20 minutes per day saved from one librarian guided training session. ${ }^{11}$

\section{Future}

The value of medical librarians will continue to grow as medical literature is increasingly distributed among a variety of resource modalities (i.e., online journals, printed books, etc.). In order to facilitate their expanded roles, medical teams should include librarians as an essential part of their multidisciplinary team.

At SAMMC, librarians routinely demonstrate their capabilities and indispensable role in providing manuscripts for medical research projects. SAMMC librarians continually widen their skillset and expertise in research and clinical medicine while maintaining their traditional responsibilities. They will continue to be utilized for teaching research methods, conducting initial literature screening and filling expanded roles to fit medical teams' needs.

\section{Conclusion}

The efforts of the San Antonio Military Medical Center library staff have resulted in multiple peer reviewed medical publications and increased physician time to spend with patients. Medical librarians are highly trained professionals that are often underutilized and unrecognized. Incorporating medical librarians into the medical team, especially a research medical team, has been shown to be advantageous, efficient, and cost effective; medical librarians are a vital but underutilized "combat multiplier".

\section{Conflicts of interest}

The authors report no conflicts of interest.

\section{Acknowledgements}

None.

\section{References}

1. Koffel JB Use of Recommended Search Strategies in Systematic Reviews and the Impact of Librarian Involvement: A Cross-Sectional Survey of Recent Authors. PLoS ONE. 2015;10(5):e0125931.

2. King SB, Lapidus M Metropolis revisited: the evolving role of librarians in informatics education for the health professions. $J$ Med Libr Assoc. 2015;103(1):14-18.

3. Nichols BF Personal Communication. 2016

4. McClure LW When the librarian was the search engine: introduction to the special issue on new roles for health sciences librarians. Journal of the Medical Library Association. 2013;101(4):257-260.

5. Cooper ID, Crum JA New activities and changing roles of health sciences librarians: a systematic review, 1990-2012. J Med Libr Assoc. 2013;101(4):268-277.

6. Maggio LA, Durieux N, Tannery NH Librarians in EvidenceBased Medicine Curricula: A Qualitative Study of Librarian Roles, Training, and Desires for Future Development. Med Ref Serv $Q$. 2015;34(4):428-440.

7. Stevenson A, Lindberg CA New Oxford American dictionary. (3rd edn), Oxford University Press. New York, USA, p. 46. 2013

8. Freiburger G, S Kramer Embedded librarians: one library's model for decentralized service. J Med Libr Assoc. 2009;97(2):139-142.

9. Aitken EM, Powelson SE, Reaume RD et al. Involving Clinical Librarians at the Point of Care: Results of a Controlled Intervention. Acad Med. 2011;86(12).

10. Madden A, Collins P, McGowan S et al. Demonstrating the financial impact of clinical libraries: a systematic review. Health Info Libr J. 2016;33(3):172-189.

11. Perrier L, Farrell A, Ayala AP et al. Effects of librarian-provided services in healthcare settings: a systematic review. J Am Med Inform Assoc. 2014;21(6):1118-1124. 